\title{
ФОРМИРОВАНИЕ ГИБКИХ НАВЫКОВ СТУДЕНТОВ ГУМАНИТАРНЫХ НАПРАВЛЕНИЙ ПОДГОТОВКИ ПРИ ИЗУЧЕНИИ ИНОСТРАННОГО ЯЗЫКА В ОНЛАЙН-СРЕДЕ
}

\section{DEVELOPING SOFT SKILS OF STUDENTS OF HUMANITIES WHILE LEARNING A FOREIGN LANGUAGE IN ONLINE ENVIRONMENT}

A. Glotova

Summary: The article is devoted to the pedagogical issues of "soft skills" development while learning a foreign language by students of Humanities in online environment. The term "soft skills" is analyzed as an essential part of foreign language professional training of students majoring in Humanities. The paper also focuses on the digitalization of learning process in the system of Higher Education in the Russian Federation. An example of project-based activities in foreign language learning is regarded, that can be used to develop such soft skills as communication, team work and self-guidance. The study presents various online tools as additional educational means to achieve the educational goals and tasks of bachelors' professional training in digital environment.

Keywords: soft skills, online learning environment, foreign language, humanitarian education, collaboration tools.

Профессиональная подготовка бакалавров на современном этапе развития системы высшего образования в Российской Федерации представляет собой целенаправленный организованный процесс, направленный на формирование готовности выпускников к деятельности в контексте технологического и цифрового обновления общества, всестороннего международного сотрудничества, кросс-культурного и межличностного взаимодействия. Происходящие изменения в обществе, связанные с повсеместным распространением технологий, стимулируют представителей мирового научного и академического сообщества к поиску инновационных подходов и определению новых методов обеспечения профессионально-ориентированной подготовки студентов [3]. В.И. Блинов выделяет 3 основных фактора, обуславливающих необходимость построения цифрового образовательного процесса:

1. внедрение положений цифровой экономики;

2. новые цифровые технологии, формирующие цифровую среду и развивающиеся в ней;

3. цифровое поколение, которое отличается определенными социальными и психолого-педагогическими особенностями, определяющими
Глотова Александра Валерьевна

Аспирант, Севастопольский государственный университет; старший преподаватель, Филиал

Московского государственного университета имени М.В. Ломоносова в г. Севастополе glotova@glotova.com

Аннотация: Статья посвящена педагогической проблеме формирования «гибких навыков» студентов гуманитарных направлений подготовки при изучении иностранного языка в онлайн-среде. Анализируется понятие «гибкие навыки как неотъемлемый компонент профессионально-ориентированной иноязычной подготовки бакалавров гуманитарных специальностей. Особое внимание уделяется вопросу цифровизации образовательного процесса в системе высшей школы в Российской Федерации. Приведен пример использования элементов проектной деятельности при изучении иностранного языка, направленной на формирование комплекса гибких навыков, например, коммуникация, групповое взаимодействие, самоорганизация. Рассматриваются категории онлайн-инструментов как вспомогательное средство достижения образовательных целей иноязычной профессиональной подготовки бакалавров в цифровой среде вуза.

Ключевые слова: гибкие навыки, образовательная онлайн-среда, иностранный язык, гуманитарное образование, инструменты совместной работы.

специфику приобретения знаний и развития необходимых навыков и умений в развивающейся среде нового типа [3, с. 12].

А.Г. Широкопояс, бизнес-тренер, эксперт по управлению персоналом, основатель портала «Компетенции» (Hr-media.ru), журналов «Компетенции» и «Компетенции руководителей», акцентирует внимание в аналитическом отчете Автономной некоммерческой организации программ дополнительного профессионального образования «Корпоративный университет Сбербанка» «Обучение цифровым навыкам: глобальные вызовы и передовые практики» на «необходимости трансформации самой парадигмы образования и пересмотре существующих подходов и моделей обучения, направленных на развитие общей цифровой грамотности, социальных и эмоциональных навыков для успеха в новом цифровом мире» [11].

В условиях цифровой трансформации вузов России и перехода на новый формат образовательного процесса профессионально-ориентированная иноязычная подготовка бакалавров гуманитарных специальностей 
представляет собой комплекс образовательных возможностей с использованием технологий цифровой дидактики, направленных на формирование универсальных, общекультурных и профессиональных компетенций, способствующих последующему осуществлению беспрепятственной коммуникации в цифровом пространстве $[14 ; 15]$.

Однако студенты, обучающиеся на гуманитарных направлениях подготовки, обладают рядом специфических характеристик, которые стоит учитывать при проектировании образовательного процесса для данной категории. Среди основных карьерных перспектив бакалавров гуманитарных специальностей можно выделить осуществление активной общественной и профессиональной деятельности, построенной на межличностной коммуникации в обновленном цифровом пространстве. О.В. Архипова, А.А. Казанцева, Е.М. Казанцева подчеркивают, что гуманитарное образование отличается мировоззренческой направленностью, ориентацией на личность и ее индивидуальность, изучение «человеческой природы», общества и культуры [1;7].

В данном исследовании мы рассматриваем проблему формирования спектра «гибких навыков» в контексте профессионально-ориентированной иноязычной подготовки студентов программы бакалавриата Филиала Московского государственного университета имени М.В. Ломоносова в г. Севастополе, обозначенных в комплексе следующих гуманитарных специальностей: 45.03.01 «Филология», 46.03.01 «История», 42.03.02 «Журналистика», 38.03 .03 «Государственное и муниципальное управление».

«Иностранный язык» входит в блок обязательных дисциплин для изучения в большинстве образовательных программ студентов бакалавриата, то есть является ядром профессионально-ориентированной иноязычной подготовки, основой культурного развития и формирования базовых личных и профессиональных качеств студентов гуманитарных направлений в вузе. Э.И. Назмиева акцентирует внимание на важности соблюдения следующих принципов организации профессионального языкового обучения специалистов гуманитарного профиля: профессиональная направленность, научность, индивидуализация, системность, функциональность, ситуативность, гуманизация, речемыслительная активность [9, с. 24]. Е.П. Звягинцева полагает, что «профессионально ориентированная иноязычная подготовка будущего специалиста включают в себя педагогические, философские, психологические и социологические знания и является процессом взаимодействия на основе коммуникативных, лингвистических, социокультурных знаний, умений и навыков, нацеленных на саморазвитие личности в профессиональной деятельности» [4]. Иноязычная профес- сиональная подготовка бакалавров также направлена на процесс формирования и развития приоритетных навыков 21 века. Например, навыки для жизни и построения карьеры (от англ. Life and Career skills), навыки для обучения и ведения инновационной деятельности (от англ. Learning and Innovation skills), а также навыки работы с информацией, медиа грамотность и владение ИКТ (от англ. Information, Media and Technology Skills) [15; 17].

На сегодняшний день особое внимание при проектировании процесса профессиональной иноязычной подготовки студентов уделяется педагогической проблеме формирования «гибких навыков» (от англ. «soft skills») (С.Г. Меньшенина, Г.А. Позднякова, С.А. Шилова и другие) [8; 16]. «Гибкие» (или мягкие) навыки охватывают широкие неспециализированные «надпрофессиональные» навыки, необходимые для осуществления трудовой деятельности в условиях неопределенности и стремительных преобразований в обществе [2]. Владение «soft skills» наиболее актуально для выпускников гуманитарных специальностей, поскольку их будущая карьера связана с аспектами межличностной коммуникации и взаимодействия с общественностью

Гибкие навыки тесно переплетаются с понятиями «личностные качества и ценности». Данная категория не относится к определенной сфере в отличие от «жестких» (от англ. «hard skills»), лежащих в основе приобретения узконаправленных профессиональных компетенций. Гибкие навыки необходимы для осуществления продуктивного межличностного взаимодействия с учетом разнообразных социально-психологических аспектов: самодисциплина, самоорганизация, умение работать в команде, коммуникация, эмоциональный интеллект.

О.Л. Чуланова характеризует гибкие навыки как «мягкие компетенции» на основе компетентностного подхода. По мнению исследователя, soft skills - «социально-трудовая характеристика знаний, умений, навыков и мотивационных характеристик работника в сфере взаимодействия между людьми, умения грамотно управлять своим временем, умения убеждать, ведения переговоров, лидерства, эмоционального интеллекта, обладающих эмерджетностью, необходимых для успешного выполнения работы...» [6, с, 4]. С.Г. Меньшенина, Г.А. Позднякова рассматривают «гибкие навыки» как комплексное явление, включающее «ряд мыслительных, коммуникативных, управленческих умений, навыков и личных качеств студентов, способствующих достижению успеха в профессиональной и личной сферах жизни» [8, c, 108].

По результатам контент-анализа педагогической, научной и методической литературы, мы считаем, что среди спектра навыков и умений, необходимых для жизни 
и построения карьеры специалистам гуманитарной направленности при изучении иностранного языка в условиях цифровизации современного общества в рамках исследования необходимо обозначить потребность в развитии следующих «гибких навыков»:

- навыки межличностного общения;

- умение работать в команде;

- гибкость и адаптируемость к стремительно меняющимся условиям;

- способность к самоопределению и самоорганизации.

Дисциплина «Иностранный язык» в условиях цифровой трансформации образовательного процесса способствует продуктивному формированию «гибких навыков». Помимо развития основополагающих коммуникативных навыков и умений в рамках курса (монологическая и диалогическая речь, решение коммуникативной задачи в ситуациях речевого этикета, формулирование основной идеи высказывания, личная аргументация и так далее), при обучении иностранному языку используются различные виды и формы самостоятельной, парной или групповой работы, направленные на вовлечение студентов в активную учебную и познавательную деятельность. Профессионально-ориентированная иноязычная подготовка бакалавров гуманитарных направлений строится на основе коммуникативно-ориентированного, системно-деятельностного, компетентностного, аксиологического и лично-ориентированных подходов. Согласно действующих ФГОС ВО в результате освоения дисциплины «Иностранный язык» у студентов гуманитарных специальностей должны быть сформированы универсальные компетенции, такие как: «Командная работа и лидерство», «Самоорганизация и саморазвитие», «Разработка и реализация проектов», направленные на овладение навыками и умениями организации эффективной совместной и самостоятельной деятельности Умение работать в команде востребовано во всех сферах профессиональной деятельности.

Е.П. Звягинцева рассматривает иноязычную подготовку студентов в рамках процесса формирования у студентов иноязычных коммуникативных способностей за счет интеграции наиболее перспективных дидактических подходов к созданию в вузе иноязычной развивающей образовательной среды [5, с. 14]. Внедрении цифровых образовательных технологий в процесс профессионально-ориентированной иноязычной подготовки бакалавров сопровождается установлением новых форм коммуникации и взаимодействия в онлайн-среде, требующих развития «гибких навыков», определяющих продуктивность педагогического взаимодействия. Например, В.И. Блинов выделяет следующие педагогические технологии для обеспечения цифрового образовательного процесса: технология сетевой коммуникации, дистанционное обучение, смешанное обучение. проектная детальность [3, с. 50].

В условиях преобразования системы высшей школы стоит отметить, что эффективная профессиональноориентированная иноязычная подготовка студентов в цифровой образовательной среде вуза проектируется в соответствии с основными положениями дидактики, а также современной разрабатываемой системы онлайнобучения, базирующейся на элементах теорий познания социального конструктивизма и коннективизма [3; 18]. Наиболее популярные методы обучения в цифровой дидактике - это проектная деятельность и взаимное обучение (от англ. «peer-to-peer learning»), основанные на групповых формах работы учащихся и совместном обсуждении проблемных вопросов. Использование методов активного вовлечения студентов в коннективистских и конструктивистских теориях обучения способствует развитию творческих способностей студентов и их «гибких навыков», необходимых для будущей успешной профессиональной деятельности.

Учебный процесс в онлайн-среде направлен на приобретение знаний и развитие навыков и умений через взаимодействие обучающихся в различных формах с использованием возможностей развивающихся технологий. Для организации цифрового образовательного процесса в Филиале МГУ имени М.В. Ломоносова используется портал дистанционной поддержки, представляющий собой электронную информационно-образовательную среду вуза (https://distant.sev.msu.ru/) [12]. Ресурс разработан на основе платформы Moodle, инструментарий которой позволяет проводить индивидуальные и групповые формы работы при изучении иностранного языка. В период перехода университетов Российской Федерации в формат электронного обучения с применением дистанционных образовательных технологий в связи с распространением коронавирусной инфекции COVID-19 в марте 2020 г. преподаватели также использовали резервные каналы коммуникации со студентами для проведения занятий, поскольку изучение иностранного языка происходит на основе коммуникативного подхода и фактор «наличия общения» является основополагающим.

При дистанционном взаимодействии продуктивным способом организации и активизации учебной и познавательной деятельности студентов считается проектная деятельность. Данная форма работы ориентирована на развитие как жестких, так и мягких навыков бакалавров. Российские вузы постепенно переходят к открытой проектной модели подготовки кадров. Например, в концепции развития деятельности НИУ ВШЭ до 2030 года профессиональная подготовка соединяется «с пониманием широкого контекста профессиональной деятельности, 
способностью не просто адаптироваться к переменам, но выстраивать собственные проекты, работать в группах, вести коммуникацию» [10].

Приведем пример организации проектной работы в рамках профессиональной иноязычной подготовки бакалавров в вузе. При поиске альтернативных решений для проведения занятий по иностранному языку в дистанционной форме студентам был предложен практико-ориентированный проект «Tools for collaborative learning and team work», нацеленный на выявление дополнительных оптимальных инструментов обеспечения совместной удаленной работы в Крыму в виду действующих санкций в регионе. Проект предусматривал 3 основных этапа, направленных на развитие личных и профессиональных навыков и умений (поиск информации, обработка данных и представление результатов на иностранном языке). Актуальность выбранной педагогической технологии была обусловлена рядом факторов: необходимость организации самостоятельной и групповой работы студентов в дистанционном формате, развитие речевых умений и гибких навыков в условиях удаленного взаимодействия, активизация познавательной и исследовательской деятельности в онлайн-среде.

На 1 этапе «Research and collecting data» студентам предлагалось изучить и отобрать современные программные решения и инструменты совместной работы, которые функционируют без ограничений на территории Крыма и не предусматривающие взнос установленной оплаты за использование сервиса. Рассматриваемые ресурсы должны решать проблемы, являющиеся также актуальными для проведения занятия по иностранному языку в виду специфики предмета и необходимы студентам для последующей профессиональной деятельности в цифровом обществе (обмен информацией и различными типами файлов, хранение данных, обеспечение коммуникации, организация совместного создания редактирования документов и презентаций, инструменты для визуализации контента и создания ментальных карт и так далее). Важным умением современного выпускника считается грамотная ориентация в информационно-образовательном пространстве.

Во время 2 этапа «Processing Data / Classification» студенты должны были проанализировать найденные решения, разгруппировать их по категориям на основе самостоятельно определенных критериев и представить результаты в виде таблицы или ментальной карты, выполненной в одном из изучаемых сервисов, например, Mind42, Coggle. В таблице 1 приведен пример оформления результатов исследования студентов в рамках 2 этапа проекта.

На заключительном 3 этапе «Project Presentation» обучающиеся представляли свои индивидуальные или групповые проекты, в которых анализировали функциональные возможности, преимущества и недостатки, а также высказывали личное мнение по результатам использования в учебном процессе выбранного сервиса на иностранном языке.

Таким образом, проектная деятельность в процессе профессионально-ориентированной иноязычной подготовки бакалавров гуманитарных специальностей нацелена на формирование следующих навыков и умений:

1. способность чётко формулировать тему, проблему, цели и задачи исследования;

2. логика выстраивания и осуществления этапов проекта;

Таблица 1.

Категории и примеры инструментов совместной работы студентов при изучении иностранного языка

\begin{tabular}{|l|l|l|}
\hline \multicolumn{1}{|c|}{ Цель использования инструментов } & \multicolumn{1}{|c|}{ Категория инструментов } & \multicolumn{1}{|c|}{ Примеры } \\
\hline Коммуникация & Web conferencing services. & $\begin{array}{l}\text { Go to Meeting, Proficonf, UberConference, TrueConf } \\
\text { online, FreeConference, Skype, etc. }\end{array}$ \\
\hline \multirow{2}{*}{ Хранение и обмен информацией } & $\begin{array}{l}\text { Group messengers with files or screen sharing } \\
\text { Options. }\end{array}$ & $\begin{array}{l}\text { the latest version of Icq, Slack, Telergram, Discord, } \\
\text { etc. }\end{array}$ \\
\cline { 2 - 3 } & $\begin{array}{l}\text { CRM (Customer Relationship Management) and } \\
\text { other project management platforms and software. }\end{array}$ & $\begin{array}{l}\text { Bitrix24, Asana, Insightly, Streak, Freedcamp, } \\
\text { MeisterTask, etc. }\end{array}$ \\
\hline \multirow{2}{*}{ Совместная работа сдокументами } & $\begin{array}{l}\text { Cloud storage for teams. } \\
\text { Визуализация материала }\end{array}$ & $\begin{array}{l}\text { pCloud, Dropbox, Yandex Disk, ShareFile, OpenKM, } \\
\text { etc. }\end{array}$ \\
\hline presentation tools. & $\begin{array}{l}\text { Google docs, Bit.ai, Google presentation, Prezi, } \\
\text { Visme, Alfresco, etc. }\end{array}$ \\
\hline Самоорганизация & Interactive Boards. & $\begin{array}{l}\text { Whiteboard, Linoit, Canva, Whiteboard Fox, } \\
\text { Megascopes, etc. }\end{array}$ \\
\cline { 2 - 4 } & Creating Mind Mapping services and applications. & Mind42, Coggle, Mindomo, Mindmeister, etc. \\
\hline
\end{tabular}


3. грамотное структурирование и отбор языковых средств аргументации и позиционирования своей точки зрения;

4. навыки и умения публичных выступлений, владение риторическими приемами на иностранном языке;

5. овладение различными мультимедийными средствами визуализации материала и основами инфографики.

Результаты выполненной работы в завершении каждого этапа проекта студенты отправляли для отчетности на портал дистанционной поддержки Филиала, используя опцию «Задание» в системе Moodle в рамках электронного курса. Кроме этого, во время проведения практических занятий проходило совместное обсуждение проблемных вопросов с преподавателями в программе BigBlueButton, которая встроена в систему портала вуза для проведения видеоконференций.

Внедрение метода проектов для развития «гибких навыков» в процессе профессионально-ориентирован- ной иноязычной подготовки бакалавров в онлайн-среде имеет практическое значение, объединяя разнообразные формы организации учебной, поисковой, исследовательской, научной и других видов деятельности, опираясь на основные требования цифровой дидактики и современного общества.

Профессиональная иноязычная подготовка студентов гуманитарных специальностей ориентирована на формирование универсальных, профессиональных компетенций, а также на развитие навыков, умений и личных качеств обучающихся в вузе, которые являются основополагающими для представителей цифрового общества. На сегодняшний день считается затруднительным определить критерии и количественные показатели сформированности «гибких навыков», поскольку они не являются постоянной величиной. Однако наличие именно «гибких навыков» определяет уровень развития личности студента и его профессиональной культуры. Дисциплина «Иностранный язык» является в этом контексте продуктивным средством достижения поставленных целей.

\section{ЛИТЕРАТУРА}

1. Архипова 0.В. Гуманитарное образование и гуманитарная педагогика: природа, специфика, цели // Общество. Среда. Развитие. 2011. № 2 (19). C. 192-195.

2. Атлас новых профессий 3.0 / под ред. Д. Варламовой, Д. Судакова. - М.: Интеллектуальная Литература, 2020. 456 с.

3. Дидактическая концепция цифрового профессионального образования и обучения / П.Н. Биленко, В.И. Блинов, М.В. Дулинов, Е.Ю. Есенина, А.М. Кондаков, И.С. Сергеев; под науч. ред. В.И. Блинова, 2020. 98 с.

4. Звягинцева Е.П., Соколова Н.И. Интегративно-развивающая образовательная среда вуза и ее влияние на процесс профессионально ориентированной иноязычной подготовки студентов // Молодой ученый. 2014. № 15 (74). С. 266-270.

5. Звягинцева Е.П. Совершенствование иноязычной подготовки студентов на основе интегративно-развивающего подхода: дис. ... канд. пед. наук. M., 2014. $218 \mathrm{C}$.

6. Ивонина А.И., Чуланова 0.Л., Давлетшина Ю.М. Современные направления теоретических и методических разработок в области управления: роль soft skills и hard skills в профессиональном и карьерном развитии сотрудников // Вестник евразийской науки. 2017. Т. 9, № 1. С. 1-18.

7. Казанцева А.А., Казанцева Е.М. Гуманитарная парадигма: к вопросу о сущности понятия // Азимут научных исследований: педагогика и психология. 2018. T. 7, № 3(24). С. 115-117.

8. Меньшенина С.Г., Позднякова Г.А. Формирование гибких навыков студентов бакалавриата в процессе обучения иностранному языку // Вестник самарского государственного технического университета. Серия «Психолого-педагогические науки». 2019. № 3(43). С. 106-115.

9. Назмиева Э.И. Иноязычная подготовка будущих специалистов гуманитарного профиля в контексте европизации высшего образования: автореф. дис. ... канд. пед. наук. Казань, 2013. 24 с.

10. Образование: переход к открытой проектной модели // Развитие основных направлений деятельности НИУ ВШЭ до 2030 г. URL: https://www.hse.ru/ prog2030/prog4\#pagetop (дата обращения: 15.01.2021).

11. Обучение цифровым навыкам: глобальные вызовы и передовые практики: аналит. отчет, АНО дПО «Корпоративный университет Сбербанка». URL: http://obzory.hr-media.ru/cifrovye_navyki_sotrudnika?fbclid=IwAR2wy-qMVpwqVd2jSq7PH37_PB60A6cLUX44W_aaHKoVbExiJrTY4wN00R4 (дата 06ращения: 15.01.2021).

12. Портал дистанционной поддержки образовательного процесса филиала МГУ в г. Севастополе. URL: https://distant.sev.msu.ru/ (дата обращения: 13.01.2021).

13. Программа «Цифровая экономика Российской Федерации» // Правительство Российской Федерации, 2017. URL: http://static.government.ru/media/files/9g FM4FHj4PsB7915v7yLVuPgu4bvR7M0.pdf (дата обращения: 16.01.2021).

14. Статья 16. Федеральный закон «0б образовании в Российской Федерации» от 29.12.2012 № 273-Ф3.

15. Федеральный государственный образовательный стандарт высшего образования по направлениям бакалавриата. URL: http://fgosvo.ru/fgosvo/92/91/4 (дата обращения: 15.01.2021). 
16. Шилова С.А. Формирование гибких навыков средствами микрогрупповых форм работы при обучении иностранному языку в вузе // Известия саратовского университета. Новая серия. Серия Акмеология образования. Психология развития. 2017. Вып. 4. С. 374-380. D0l: https://doi.org/10.18500/23049790-2017-6-4-374-380

17. Framework for 21st Century Learning Definitions, 2019. Learning21st Century Skills. Partnership for 21st Century. Retrieved from Battle for Kids non-for-profit organization website. URL: http://www.battelleforkids.org/networks/p21/frameworks-resources (дата обращения: 19.02.2020)

18. Picciano A.G. Theories and frameworks for online education: Seeking an integrated model. Online Learning. 2017. V. 21(3). P. 166-190.

( Глотова Александра Валерьевна (glotova@glotova.com).

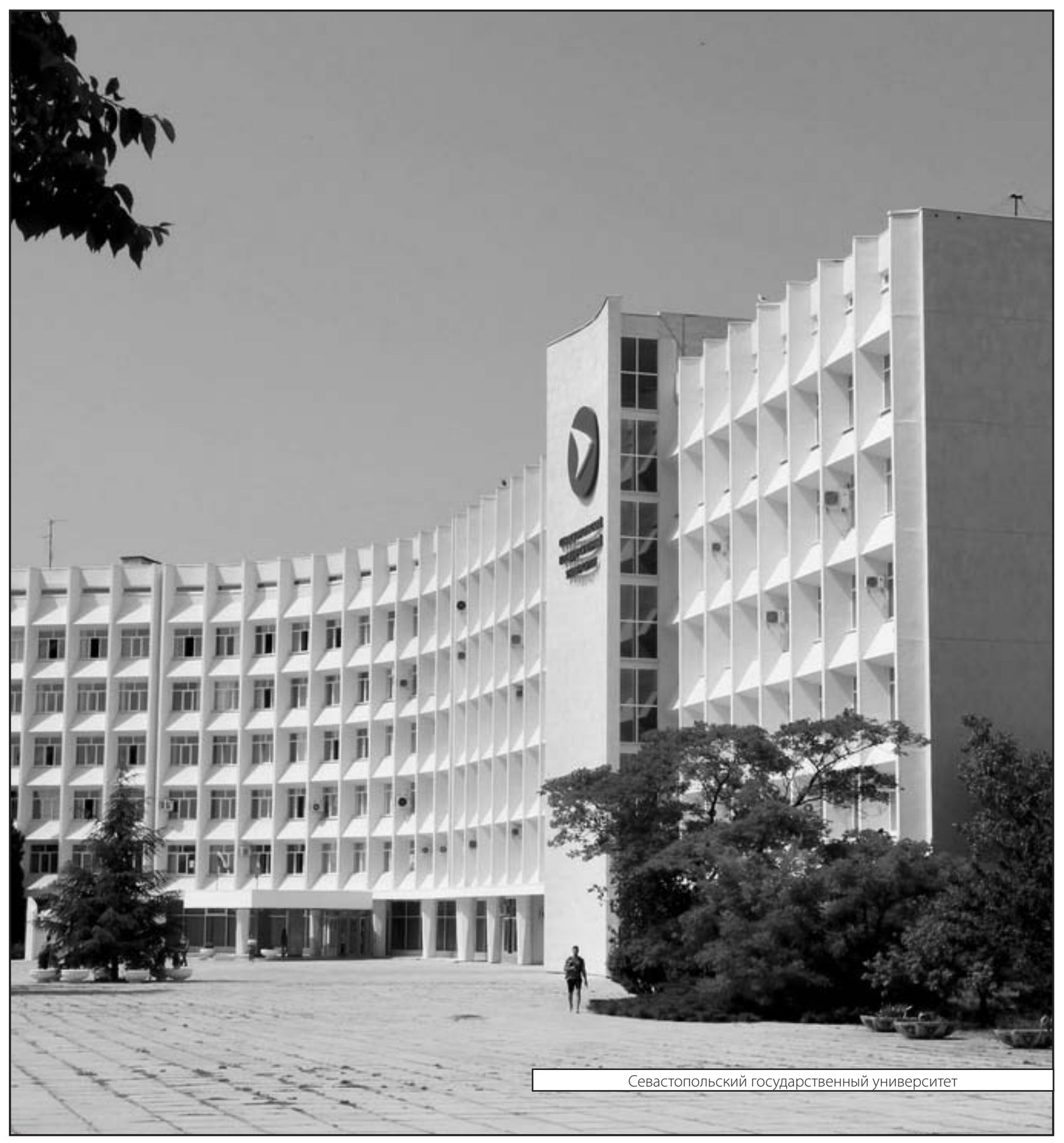

